\title{
Living Metathesis Polymerization of Several Substituted Acetylenes by $\mathrm{MoOCl}_{4}-\mathrm{Et}_{3} \mathrm{Al}-\mathrm{EtOH}$
}

\author{
Hisayasu Kaneshiro, Shigetaka Hayano, and Toshio Masuda ${ }^{\dagger}$ \\ Department of Polymer Chemistry, Graduate School of Engineering, Kyoto University, \\ Kyoto 606-8501, Japan
}

(Received October 16, 1998)

\begin{abstract}
Living polymerization of several substituted acetylenes such as [o-(trimethylsilyl)phenyl $]$ acetylene $\left(o-\mathrm{Me}_{3} \mathrm{Si}_{-}\right.$ phenylacetylene), 1-chloro-1-octyne, (o-methylphenyl)acetylene (o-Me-phenylacetylene) was investigated by using a $\mathrm{MoOCl}_{4}-$ based catalyst, $\mathrm{MoOCl}_{4}-\mathrm{Et}_{3} \mathrm{Al}-\mathrm{EtOH}(1: 1: 3-4)$. It was proved that $o-\mathrm{Me}_{3} \mathrm{Si}$-phenylacetylene polymerizes in a living fashion with the $\mathrm{MoOCl}_{4}-\mathrm{Et}_{3} \mathrm{Al}-\mathrm{EtOH}$ catalyst in the temperature range $0-30^{\circ} \mathrm{C}$. The $M_{w} / M_{n}$ was as small as 1.05 . The absolute $M_{n}$ values of poly $\left(o-\mathrm{Me}_{3} \mathrm{Si}\right.$-phenylacetylene) were determined by vapor pressure osmometry (VPO), and the following relationship was obtained; $M_{n}(\mathrm{VPO})=1.28 \times M_{n}(\mathrm{GPC}$; polystyrene calibration). The activation parameters for the polymerization of $o-\mathrm{Me}_{3} \mathrm{Si}$-phenylacetylene were determined as $\Delta H^{\neq}=73 \mathrm{~kJ} \mathrm{~mol}^{-1}$ and $\Delta S^{\neq}=-13 \mathrm{~J} \mathrm{~mol}^{-1} \mathrm{~K}^{-1}$. $\mathrm{MoOCl}_{4}-\mathrm{Et}_{3} \mathrm{Al}-\mathrm{EtOH}$ induced the living polymerization of 1-chloro-1-octyne as well to give a polymer with small polydispersity. Polymerization of $o$-Mephenylacetylene formed a stereoregular living polymer having an $M_{w} / M_{n}$ of 1.2 and $90 \%$ cis structure. Polymerizations of a few other phenylacetylenes having bulky ortho substituents also yielded living polymers, which is a tendency similar to those with previous $\mathrm{MoOCl}_{4}$-based catalysts.
\end{abstract}

KEY WORDS Living Metathesis Polymerization / Molybdenum Catalyst / Substituted Acetylene / Ternary Catalyst / Stereoregularity /

Use of transition metal catalysts enables the synthesis of polymers from various monomers such as $\alpha$-olefins, cycloolefins and acetylenes, which hardly polymerize in other polymerization processes. ${ }^{1}$ In recent years, a variety of living polymerizations have been achieved by using transition-metal catalysts, typical examples of which are living polymerization of $\alpha$-olefins ${ }^{2-5}$ and living ringopening metathesis polymerization (ROMP) of cycloolefins. ${ }^{6-8}$ Living polymerization of substituted acetylenes has also been accomplished by use of several transition-metal catalysts including Schrock carbenes, ${ }^{9-13}$ $\mathrm{MoOCl}_{4}$-based catalysts, ${ }^{14-16}$ and rhodium complexes. ${ }^{17,18}$ Schrock carbenes induce the living polymerization of $\alpha, \omega$-diynes, ${ }^{9,10}$ ethynylferrocene, ${ }^{11}$ and orthosubstituted phenylacetylenes. ${ }^{12,13}$ Certain rhodium-based catalysts polymerize phenylacetylene in a living manner to give a stereoregular living polymer. ${ }^{17,18}$

Previously, we found that the $\mathrm{MoOCl}_{4}-n-\mathrm{Bu}_{4} \mathrm{Sn}-$ $\mathrm{EtOH} /$ toluene (catalyst/solvent) system effects the living polymerization of various substituted acetylenes such as ortho-substituted phenylacetylenes, 1-chloro-1-alkynes and $t$-butylacetylene. ${ }^{14,15}$ Our recent studies on the $\mathrm{MoOCl}_{4}$-based catalysts have focused on the availability of cocatalysts. ${ }^{19-22}$ It was consequently found that $\mathrm{Et}_{2} \mathrm{Zn}^{19}$ and $n$ - $\mathrm{BuLi}^{20}$ work as effective cocatalysts in the $\mathrm{MoOCl}_{4}$-cocatalyst-EtOH system to achieve excellent living polymerization of [o-(trifluoromethyl)phenyl]acetylene $\left(o-\mathrm{CF}_{3}\right.$-phenylacetylene). In both cases, poly$\left(o-\mathrm{CF}_{3}\right.$-phenylacetylene) with quite narrow molecular weight distribution (MWD) $\left(M_{w} / M_{n}<1.03\right)$ is attainable in quantitative yield. Interestingly, the living polymerization of substituted acetylenes is accomplished without ethanol as the third component when $n$-BuLi is employed as a cocatalyst.

As a part of our studies on the development of novel $\mathrm{MoOCl}_{4}$-based catalysts, we recently reported that a new

$\dagger^{\dagger}$ To whom correspondence should be addressed. catalyst/solvent system, $\mathrm{MoOCl}_{4}-\mathrm{Et}_{3} \mathrm{Al}-\mathrm{EtOH} /$ anisole, polymerizes $o-\mathrm{CF}_{3}$-phenylacetylene in a living fashion. ${ }^{21}$ Poly (o- $\mathrm{CF}_{3}$-phenylacetylene) with very narrow MWD was obtained in quantitative yield. In the present study, we applied this catalyst system to various substituted acetylenes aiming at clarifying the features of the polymerization catalyzed by the $\mathrm{MoOCl}_{4}-\mathrm{Et}_{3} \mathrm{Al}-\mathrm{EtOH} /$ anisole system.

\section{EXPERIMENTAL}

The monomers such as $o-\mathrm{Me}_{3} \mathrm{Si}$-phenylacetylene, 1chloro-1-octyne, $o$-Me-phenylacetylene were prepared with reference to the literature methods. ${ }^{23-25}$ The crude products were distilled twice from $\mathrm{CaH}_{2}$ before use. $\mathrm{MoOCl}_{4}$ was used as received (Strem, purity >99\%). $\mathrm{Et}_{3} \mathrm{Al}$ was commercially obtained as $1.0 \mathrm{M}$ toluene solution and diluted with anisole to a $0.10 \mathrm{M}$ solution. $n$ - $\mathrm{Bu}_{4} \mathrm{Sn}$ and $\mathrm{EtOH}$ were distilled before use. After removal of benzaldehyde by using (2,4-dinitrophenyl)hydrazine, anisole was washed twice with aqueous $\mathrm{NaOH}$ solution, followed by distilling twice from $\mathrm{Na}$ under a nitrogen atmosphere.

Catalyst solution was prepared as follows: $\mathrm{MoOCl}_{4}$ $(50 \mu \mathrm{mol})$ was weighed under nitrogen and placed in a Schlenk tube, and anisole $(2.0 \mathrm{~mL})$ was added. An anisole solution $(0.50 \mathrm{~mL})$ of $\mathrm{Et}_{3} \mathrm{Al}(50 \mu \mathrm{mol})$ and an anisole solution $(0.5 \mathrm{~mL})$ of EtOH $(200 \mu \mathrm{mol})$ were successively added to the $\mathrm{MoOCl}_{4}$ solution at 1 min interval, and the catalyst solution was aged for $15 \mathrm{~min}$ with stirring. Then polymerization was initiated by adding an anisole solution $(2.0 \mathrm{~mL})$ of monomer $(1.0 \mathrm{mmol})$ to the catalyst solution. The polymerization was quenched with a methanol/acetic acid/anisole mixture (volume ratio $1: 1: 1)$. The polymerization mixture was washed with $5 \%$ hydrochloric acid and then water, and subsequent evaporation of the volatile materials afforded polymer. In the case of $o$-Me-phenylacetylene, the polymerization 
Time, $\mathrm{h}$

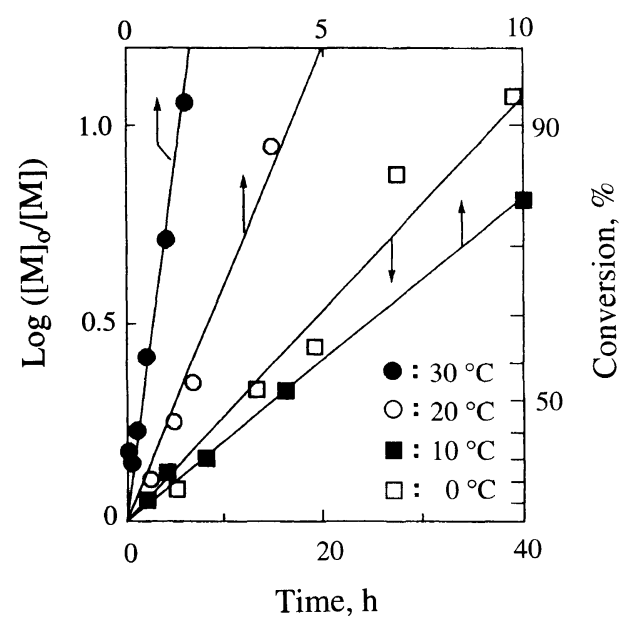

(a)
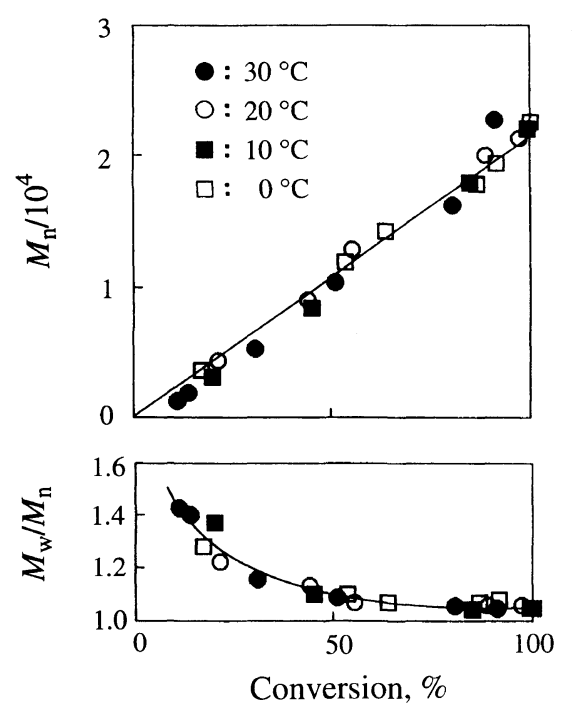

(b)

Figure 1. Temperature dependence of the polymerization of $o-\mathrm{Me}_{3} \mathrm{Si}$ phenylacetylene by $\mathrm{MoOCl}_{4}-\mathrm{Et}_{3} \mathrm{Al}-\mathrm{EtOH}(1: 1: 4)$; (a) first-order plots, (b) plots of monomer conversion vs. $M_{n}$ and vs. $M_{w} / M_{n}$ (polymerized in anisole; $\left[\mathrm{MoOCl}_{4}\right]=10 \mathrm{mM},[\mathrm{M}]_{0}=0.20 \mathrm{M}$ ).

mixture was diluted with toluene and reprecipitated into methanol. The monomer conversions were determined by gas chromatography. The polymer yields were determined by gravimetry.

The MWD's of polymers were recorded on a gelpermeation chromatograph (GPC) (JASCO PU930; eluent chloroform; Shodex K805, 804, 803, and K802 polystyrene gel columns; RI detector). The relative number- and weight-average molecular weights $\left(M_{n}\right.$ and $M_{w}$, respectively) were calculated by use of a polystyrene calibration. The absolute $M_{n}$ values were determined by vapor pressure osmometry (VPO) with a Knauer vapor pressure osmometer (solvent: $\mathrm{CCl}_{4}$; standard: dibenzyl). The polymer samples used were purified by fractionation using a preparative GPC (JASCO PU930; eluent chloroform; Shodex H2001 column; RI detector) followed by freeze-drying of benzene solution at $0^{\circ} \mathrm{C} .{ }^{13} \mathrm{C}$ NMR spectra of polymers were measured in $\mathrm{CDCl}_{3}$ at room temperature on a JEOL GSX-270 spectrometer $(67.5$ $\mathrm{MHz}$ for ${ }^{13} \mathrm{C}$ ).

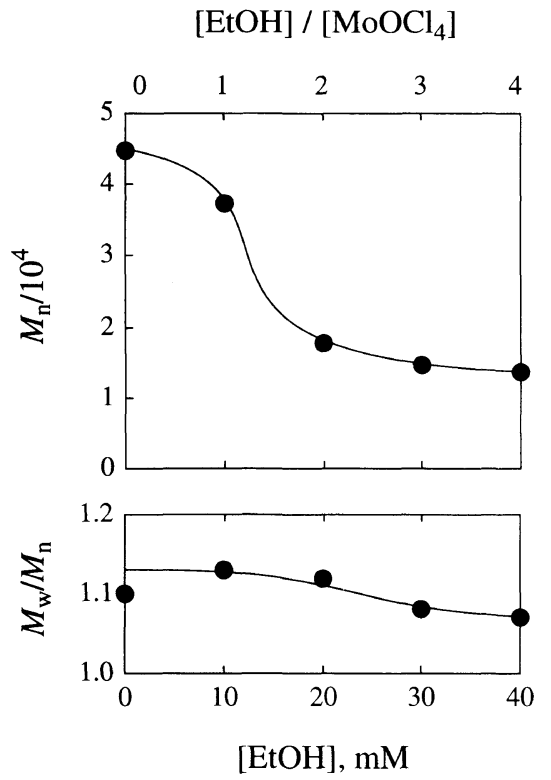

Figure 2. Effect of ethanol concentration on the polymerization of $o-\mathrm{Me}_{3} \mathrm{Si}$-phenylacetylene by $\mathrm{MoOCl}_{4}-\mathrm{Et}_{3} \mathrm{Al}-\mathrm{EtOH}(1: 1: x)$ (polymerized in anisole at $30^{\circ} \mathrm{C}$; $\left[\mathrm{MoOCl}_{4}\right]=10 \mathrm{mM},[\mathrm{M}]_{0}=0.10 \mathrm{M}$, all the conversions were $100 \%$ )

\section{RESULTS AND DISCUSSION}

\section{Living Polymerization of o-Me $\mathrm{C}_{3} \mathrm{Si}$-Phenylacetylene}

Figure 1 shows the time dependence of the polymerization of $o-\mathrm{Me}_{3} \mathrm{Si}$-phenylacetylene using $\mathrm{MoOCl}_{4}-\mathrm{Et}_{3} \mathrm{Al}-$ $\mathrm{EtOH}(1: 1: 4)$. The polymerization was finished within $2 \mathrm{~h}$ at $30^{\circ} \mathrm{C}$, while it took $50 \mathrm{~h}$ at $0^{\circ} \mathrm{C}$ for the completion of the polymerization. The first-order plots gave a single straight line passing through the origin, indicating that the concentration of propagating species is constant throughout the polymerization and independent of temperature in the range $0-30^{\circ} \mathrm{C}$. The $M_{n}$ increased in direct proportion to the monomer conversion, and the MWD narrowed with increasing conversion to become as small as 1.05 at high conversions. Thus, one can conclude that this polymerization is a living system.

The effect of ethanol concentration was examined in the range of $[\mathrm{EtOH}]=0-40 \mathrm{mM}$, i.e., [EtOH]/ $\left[\mathrm{MoOCl}_{4}\right]=1-4$ (Figure 2). Though a narrow MWD was attained without the addition of ethanol to the catalyst $\left(M_{w} / M_{n} \sim 1.1\right)$, the $M_{n}$ was rather large, meaning that the initiator efficiency was rather low $(\sim 4 \%)$. The $M_{n}$ decreased with increasing amount of ethanol, and the initiator efficiency became $13 \%$ at $[\mathrm{EtOH}]=40 \mathrm{mM}$. Meanwhile, the $M_{w} / M_{n}$ diminished to 1.08 . These results reveal that addition of a four-fold excess of ethanol is preferable to achieve excellent living polymerization of $o$ - $\mathrm{Me}_{3} \mathrm{Si}$-phenylacetylene.

In order to estimate the absolute values of initiator efficiency and propagation rate constant $\left(k_{\mathrm{p}}\right)$, absolute $M_{n}$ values were determined by VPO. Figure 3 depicts the plot of $M_{n}$ (VPO) vs. $M_{n}$ (GPC), which gave the following relationship: $M_{n}(\mathrm{VPO})=1.28 \times M_{n}(\mathrm{GPC}$; polystyrene calibration). The absolute initiator efficiency was calculated from this relationship and the results of Figure 1(b) was $11 \%$; cf. the value based on GPC $14 \%$. The propagation rate constants were: $0.37 \mathrm{M}^{-1} \mathrm{~s}^{-1}\left(30^{\circ} \mathrm{C}\right)$, $0.13\left(20^{\circ} \mathrm{C}\right), 0.039\left(10^{\circ} \mathrm{C}\right), 0.014\left(0^{\circ} \mathrm{C}\right)$.

Ahrrenius plot of the $k_{\mathrm{p}}$ values (Figure 4) provided 


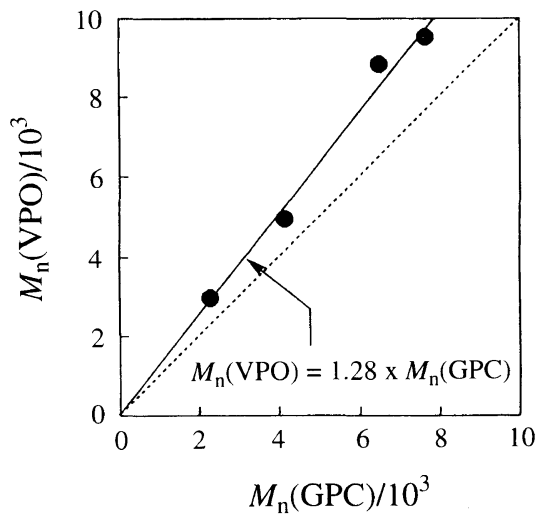

Figure 3. Relationship between $M_{n}$ (GPC) and $M_{n}$ (VPO) of poly $\left(o-\mathrm{Me}_{3} \mathrm{Si}\right.$-phenylacetylene)s obtained with $\mathrm{MoOCl}_{4}-\mathrm{Et}_{3} \mathrm{Al}-\mathrm{EtOH}$ $(1: 1: 4)$.

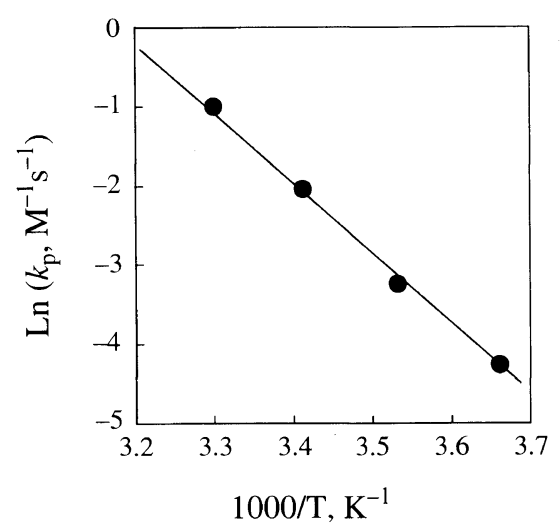

Figure 4. Ahrrenius plot of the propagation rate constant in the polymerization of $o-\mathrm{Me}_{3} \mathrm{Si}$-phenylacetylene by $\mathrm{MoOCl}_{4}-\mathrm{Et}_{3} \mathrm{Al}-\mathrm{EtOH}$ $(1: 1: 4)$ (polymerized in anisole; $\left[\mathrm{MoOCl}_{4}\right]=10 \mathrm{mM},[\mathrm{M}]_{0}=0.20 \mathrm{M}$ ).

the activation parameters for the polymerization of $o$ $\mathrm{Me}_{3} \mathrm{Si}$-phenylacetylene by $\mathrm{MoOCl}_{4}-\mathrm{Et}_{3} \mathrm{Al}-\mathrm{EtOH}(1: 1$ : 4): $\Delta H^{\neq}=73 \mathrm{~kJ} \mathrm{~mol}^{-1}, \Delta S^{\neq}=-13 \mathrm{~J} \mathrm{~mol}^{-1} \mathrm{~K}^{-1}$. The activation parameters for $o-\mathrm{CF}_{3}$-phenylacetylene are $\Delta H^{\neq}=78 \mathrm{~kJ} \mathrm{~mol}^{-1}$ and $\Delta S^{\neq}=17 \mathrm{~J} \mathrm{~mol}^{-1} \mathrm{~K}^{-1} .{ }^{21}$ Since the polymerization is the first order with respect to the monomer concentration, it seems that the rate-determining step is the coordination of a monomer to the propagating species irrespective of the monomer structure. The activation enthalpies hardly depend on the monomer structure and are much larger than the entropy terms. On the other hand, the activation entropy varies considerably depending on the monomers, which might be due to the difference in the bulkiness of orthosubstituents.

\section{Living Polymerization of 1-Chloro-1-octyne}

Figure 5 illustrates the effect of ethanol concentration on the polymerization of 1-chloro-1-octyne by $\mathrm{MoOCl}_{4}-$ $\mathrm{Et}_{3} \mathrm{Al}-\mathrm{EtOH} /$ anisole. With increasing ethanol concentration to 20 and $30 \mathrm{mM}$, the MWD narrowed and simultaneously the $M_{n}$ decreased, i.e., the initiator efficiency increased. This is the same tendency as the cases of $o-\mathrm{CF}_{3}-$ and $o-\mathrm{Me}_{3} \mathrm{Si}$-phenylacetylenes. However, when a four-fold excess of ethanol was added, polymerization was not finished in $1 \mathrm{~h}$ and further the polymer had a rather broad MWD.

The time profile of the polymerization of 1-chloro-1-
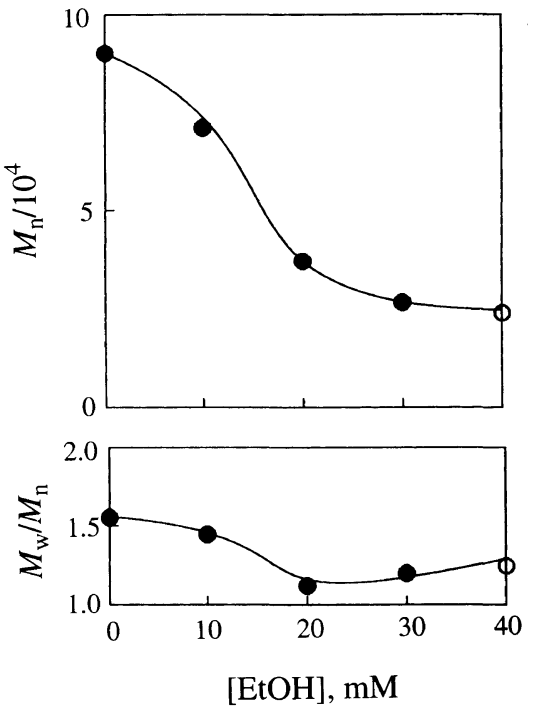

Figure 5. Effect of ethanol concentration on the polymerization of 1-chloro-1-octyne by $\mathrm{MoOCl}_{4}-\mathrm{Et}_{3} \mathrm{Al}-\mathrm{EtOH}(1: 1: x)$; (polymerized in anisole at $30^{\circ} \mathrm{C} ;\left[\mathrm{MoOCl}_{4}\right]=10 \mathrm{mM},[\mathrm{M}]_{0}=0.10 \mathrm{M}$, all the conversions were $100 \%$ ).

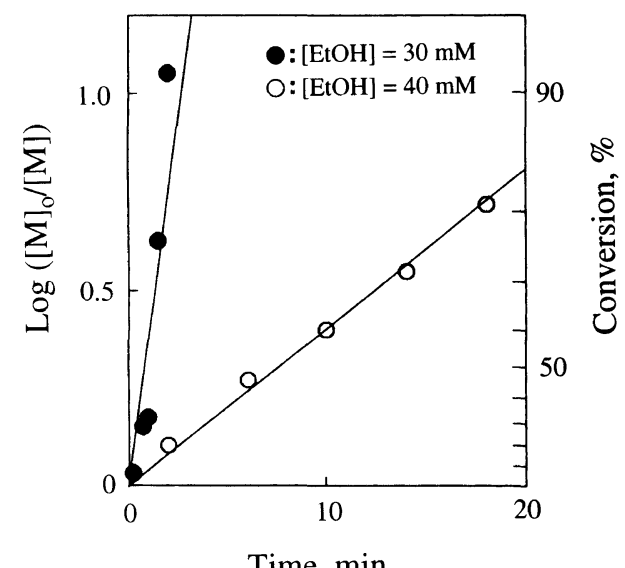

Time, $\min$

(a)
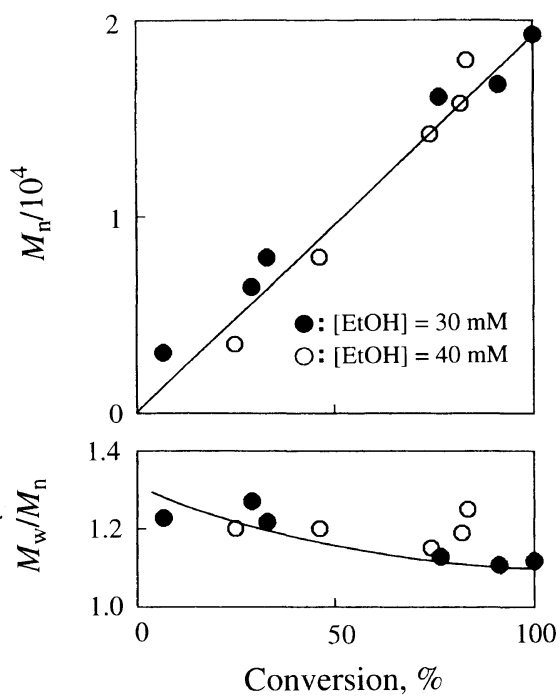

(b)

Figure 6. Polymerization of 1-chloro-1-octyne by $\mathrm{MoOCl}_{4}-\mathrm{Et}_{3} \mathrm{Al}-$ EtOH (1:1:3-4); (a) first-order plots, (b) plots of monomer conversion vs. $M_{n}$ and vs. $M_{w} / M_{n}$ (polymerized in anisole at $30^{\circ} \mathrm{C}$; $\left.\left[\mathrm{MoOCl}_{4}\right]=10 \mathrm{mM},[\mathrm{M}]_{0}=0.10 \mathrm{M}\right)$. 

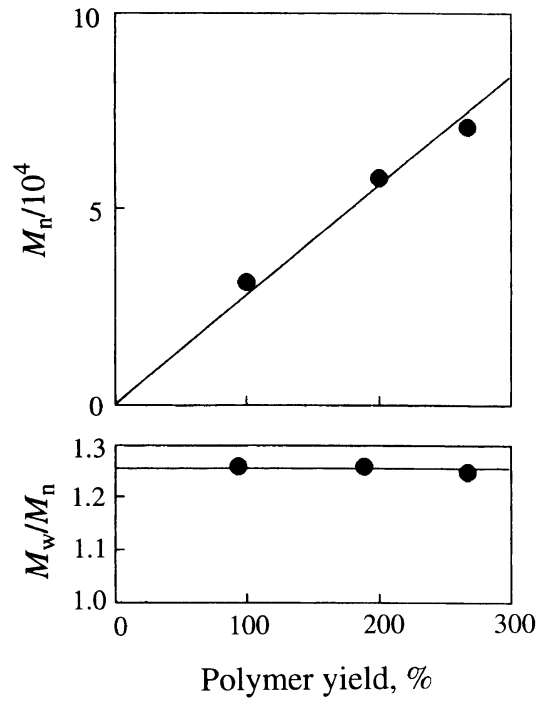

Figure 7. Multistage polymerization of $o$-Me-phenylacetylene by $\mathrm{MoOCl}_{4}-\mathrm{Et}_{3} \mathrm{Al}$ - $\mathrm{EtOH}(1: 1: 4)$ (polymerized in anisole at $0^{\circ} \mathrm{C}$. $\left.\left[\mathrm{MoOCl}_{4}\right]=10 \mathrm{mM},[\mathrm{M}]_{0}=[\mathrm{M}]_{\text {added }}=0.10 \mathrm{M}\right)$.

octyne was examined at $[\mathrm{EtOH}]=30$ and $40 \mathrm{mM}$ (Figure 6). When $\mathrm{MoOCl}_{4}-\mathrm{Et}_{3} \mathrm{Al}-\mathrm{EtOH}(1: 1: 3)$ was employed, both the first-order plot and the conversion $-M_{n}$ plot showed straight lines passing through the origin, and the MWD stayed narrow. These results manifest that this polymerization is a living system. On the other hand, in the case of $[\mathrm{EtOH}]=40 \mathrm{mM}$, the MWD broadened at a late stage, and the polymerization leveled off at $c a .80 \%$ conversion.

\section{Stereospecific Living Polymerization of o-Me-Phenylacet- ylene}

$o$-Me-Phenylacetylene polymerized in a living fashion with $\mathrm{MoOCl}_{4}-\mathrm{Et}_{3} \mathrm{Al}-\mathrm{EtOH} /$ anisole similarly to $o-\mathrm{CF}_{3}$ and $o-\mathrm{Me}_{3} \mathrm{Si}$-phenylacetylenes, though the polymerization was faster and the MWD was somewhat broader. Thus, in the multistage polymerization of $o$-Me-phenylacetylene, the $M_{n}$ increased in proportion to polymer yield, while the $M_{w} / M_{n}$ remained below $1.3^{26}$ (Figure 7).

The $c$ is content of poly $(o$-Me-phenylacetylene) can be evaluated by ${ }^{13} \mathrm{C} \mathrm{NMR}$. The living polymer $\left(M_{w} / M_{n} 1.2\right)$ obtained with $\mathrm{MoOCl}_{4}-n-\mathrm{Bu}_{4} \mathrm{Sn}-\mathrm{EtOH} /$ toluene at $-30^{\circ} \mathrm{C}$ possesses a relatively high cis content $(77 \%){ }^{27}$ It is noteworthy that the $\mathrm{MoOCl}_{4}-\mathrm{Et}_{3} \mathrm{Al}-\mathrm{EtOH}(1: 1: 4)$ forms a living poly $(o$-Me-phenylacetylene) with high stereoregularity $\left(M_{w} / M_{n} \sim 1.2\right.$, cis $\left.90 \%\right)$ (Table I). This polymer can be called a stereoregular living polymer. In contrast, the cis content of the polymer formed without ethanol was no more than $61 \%$. A similar but more remarkable tendency has been observed with $t$-butylacetylene. ${ }^{28}$ That is, the polymerization of $t$-butylacetylene with $\mathrm{MoOCl}_{4}-n-\mathrm{Bu}_{4} \mathrm{Sn}-\mathrm{EtOH} /$ toluene leads to a stereoregular living polymer $\left(M_{w} / M_{n} \sim 1.12\right.$, cis $\left.97 \%\right)$, whereas the polymerization with $\mathrm{MoOCl}_{4}$ provides a polymer with only $57 \%$ cis. These phenomena can be explained in terms that the geometric isomerization undergoes under more acidic conditions like the $\mathrm{MoOCl}_{4}$ alone or $\mathrm{MoOCl}_{4}-$ cocatalyst systems.

\section{Polymerization of Other Acetylenes}

The effect of bulkiness of ortho-substituents was
Table I. Effect of ethanol concentration on the polymerization of $o$-Me-phenylacetylene by $\mathrm{MoOCl}_{4}-\mathrm{Et}_{3} \mathrm{Al}-\mathrm{EtOH}^{\mathrm{a}}$

\begin{tabular}{ccccc}
\hline [EtOH] $/ \mathrm{mM}$ & Polymer yield $/ \%^{\mathrm{b}}$ & $M_{n}{ }^{\mathrm{c}}$ & $M_{\boldsymbol{w}} / M_{n}{ }^{\mathrm{c}}$ & $c i s / \%^{\mathrm{d}}$ \\
\hline 0 & 21 & 39600 & 3.52 & 61 \\
10 & 97 & 148500 & 4.05 & 70 \\
20 & 97 & 57000 & 1.17 & 76 \\
30 & 96 & 38800 & 1.19 & 88 \\
40 & 90 & 40900 & 1.24 & 90 \\
50 & 83 & 51300 & 1.16 & 80 \\
60 & 61 & 41700 & 1.18 & 82
\end{tabular}

${ }^{a}$ Polymerized in anisole at $0^{\circ} \mathrm{C}$ for $15 \mathrm{~min} ;\left[\mathrm{MoOCl}_{4}\right]=10 \mathrm{mM}$. ${ }^{\mathrm{b}}$ Methanol-insoluble part. ${ }^{\mathrm{c}}$ Determined by GPC. ${ }^{\mathrm{d}}$ Determined by ${ }^{13} \mathrm{C}$ NMR.

Table II. Polymerization of various ortho-substituted phenylacetylenes by $\mathrm{MoOCl}_{4}-\mathrm{Et}_{3} \mathrm{Al}-\mathrm{EtOH}^{\mathrm{a}}$

\begin{tabular}{|c|c|c|c|c|}
\hline \multirow{2}{*}{ Monomer } & Polymn. time & \multirow{2}{*}{$\begin{array}{l}\text { Polymer } \\
\text { yield } / \%\end{array}$} & \multirow{2}{*}{$M_{n}$} & \multirow{2}{*}{$M_{w} / M_{n}$} \\
\hline & $\min$ & & & \\
\hline $\mathrm{HC} \equiv \mathrm{CC}_{6} \mathrm{H}_{5}$ & 120 & 40 & 3200 & 2.62 \\
\hline $\mathrm{HC} \equiv \mathrm{CC}_{6} \mathrm{H}_{4}-o-\mathrm{F}$ & 120 & 46 & 4800 & 2.10 \\
\hline $\mathrm{HC} \equiv \mathrm{CC}_{6} \mathrm{H}_{4}-o-\mathrm{Cl}$ & 1 & 100 & 23500 & 1.30 \\
\hline $\mathrm{HC} \equiv \mathrm{CC}_{6} \mathrm{H}_{4}-o-i-\mathrm{Pr}$ & 1 & 100 & 37200 & 1.14 \\
\hline
\end{tabular}
$\mathrm{M}$

${ }^{\text {a }}$ Polymerized in anisole at $30^{\circ} \mathrm{C} ;\left[\mathrm{MoOCl}_{4}\right]=10 \mathrm{mM},[\mathrm{M}]_{0}=0.10$

examined in the polymerization of phenylacetylenes by $\mathrm{MoOCl}_{4}-\mathrm{Et}_{3} \mathrm{Al}-\mathrm{EtOH} /$ anisole (Table II). Phenylacetylene itself and $o$-F-phenylacetylene, whose ortho-substituent is sterically hardly demanding, produced polymers having broad MWD's. On the other hand, o$\mathrm{Cl}$-phenylacetylene and $o-i$-Pr-phenylacetylene, which possess medium-sized ortho-substituents, gave polymers with narrow MWD's. Thus one can see that the MWD narrows with increase in the bulkiness of orthosubstituent. This tendency is the same as in previously developed systems such as $\mathrm{MoOCl}_{4}-n-\mathrm{Bu}_{4} \mathrm{Sn}-\mathrm{EtOH} /$ toluene, ${ }^{29} \mathrm{MoOCl}_{4}-\mathrm{Et}_{2} \mathrm{Zn}-\mathrm{EtOH} /$ anisole, ${ }^{19}$ and $\mathrm{MoOCl}_{4}-n-\mathrm{BuLi} /$ anisole. ${ }^{20}$ This means that steric effect of ortho-substituents in phenylacetylene plays a vital role in achieving living polymerization by using $\mathrm{MoOCl}_{4}$ based catalysts.

\section{CONCLUSIONS}

In the present and preceding ${ }^{21}$ studies, we applied $\mathrm{MoOCl}_{4}-\mathrm{Et}_{3} \mathrm{Al}-\mathrm{EtOH} / \mathrm{anisole}$ system to various substituted acetylenes aiming at clarifying the features of polymerizations induced by this system. Eventually, the present study revealed the following: (i) $o-\mathrm{Me}_{3} \mathrm{Si}$-phenylacetylene gave a living polymer which has a very narrow MWD; (ii) 1-chloro-1-octyne also polymerized in a living fashion; and (iii) $o$-Me-phenylacetylene yielded a stereoregular living polymer. The following points can be referred to as features of the present $\mathrm{MoOCl}_{4}-\mathrm{Et}_{3} \mathrm{Al}-$ $\mathrm{EtOH} /$ anisole system as compared with $\mathrm{MoOCl}_{4}-n$ $\mathrm{Bu}_{4} \mathrm{Sn}-\mathrm{EtOH} /$ toluene: (1) higher initiator efficiencies for various monomers; e.g., [P*]/[Cat] $20 \%$ vs. $10 \%$ for $o-\mathrm{CF}_{3}$-phenylacetylene, $14 \%$ vs. $13 \%$ for $o-\mathrm{Me}_{3} \mathrm{Si}-$ phenylacetylene, $14 \%$ vs. $3 \%$ for 1-chloro-1-octyne; (2) low polydispersity ratios for various polymers; e.g., 
$M_{w} / M_{n} 1.02 v s .1 .10$ for poly $\left(o-\mathrm{CF}_{3}\right.$-phenylacetylene $)$, 1.03 vs. 1.07 for poly(o-Me ${ }_{3} \mathrm{Si}$-phenylacetylene), $1.10 v s$. 1.20 for poly(1-chloro-1-octyne); (3) high reproducibility in catalyst preparation and polymerization, which enables detailed studies on the polymerization kinetics.

Acknowledgments. We thank Dr. R. Nomura for helpful discussion. This work was supported by NEDO for the project on Technology for Novel High-Functional Materials in Industrial Science and Technology Frontier Program, AIST. SH acknowledges the support by JSPS Research Fellowships for Young Scientists.

\section{REFERENCES AND NOTES}

1. S. Kobayashi, Ed., "Catalysis in Precision Polymerization," Wiley, Chichester, 1997

2. J. D. Scollard and D. H. McConville, J. Am. Chem. Soc., 118 10008 (1996).

3. C. M. Killian, D. J. Tempel, L. K. Johnson, and M. Brookhart, J. Am. Chem. Soc., 118, 11664 (1996).

4. K. Mashima, S. Fujiwara, Y. Tanaka, H. Urata, T. Oshiki, E. Tanaka, and A. Nakamura, Organometallics, 14, 2633 (1995).

5. B. L. Small, M. Brookhart, and A. M. A. Bennett, J. Am. Chem. Soc., 120, 4049 (1998).

6. S. T. Nguyan, L. K. Johnson, and R. H. Grubbs, J. Am. Chem. Soc., 114, 3974 (1992).

7. S. T. Nguyan, R. H. Grubbs, and J. W. Ziller, J. Am. Chem. Soc., 115, 9858 (1993).

8. E. L. Dias, S. T. Nguyan, and R. H. Grubbs, J. Am. Chem. Soc., 119, 3887 (1997).

9. H. H. Fox and R. R. Schrock, Organometallics, 11, 2763 (1992).

10. H. H. Fox, M. O. Wolf, R. O'Dell, B. L. Lin, R. R. Schrock, and M. S. Wrighton, J. Am. Chem. Soc., 116, 2827 (1994).
11. M. Bachmeiser and R. R. Schrock, Macromolecules, 28, 6642 (1995).

12. R. R. Schrock, S. Luo, N. Zanetti, and H. H. Fox, Organometallics, 13, 3396 (1994).

13. R. R. Schrock, S. Luo, J. C. Lee, N. Zanetti, and W. M. Davis, J. Am. Chem. Soc., 118, 3883 (1996).

14. T. Masuda, T. Yoshimura, J. Fujimori, and T. Higashimura, $J$. Chem. Soc., Chem. Commun., 1805 (1987).

15. T. Masuda, S. Hayano, E. Iwawaki, and R. Nomura, J. Mol. Catal. A, 133, 213 (1998).

16. S. Hayano, H. Kaneshiro, and T. Masuda, Kobunshi Ronbunshu, 54, 587 (1997).

17. Y. Kishimoto, P. Eckerle, T. Miyatake, T. Ikariya, and R. Noyori, J. Am. Chem. Soc., 116, 12131 (1994).

18. Y. Kishimoto, T. Miyatake, T. Ikariya, and R. Noyori, Macromolecules, 29, 5054 (1996).

19. S. Hayano and T. Masuda, Macromol. Chem. Phys., 198, 3041 (1997).

20. S. Hayano and T. Masuda, Macromolecules, 31, 3170 (1998).

21. H. Kaneshiro, S. Hayano, and T. Masuda, Macromol. Chem. Phys., 200, 113 (1999).

22. T. Masuda, H. Kaneshiro, S. Hayano, Y. Misumi, and L. Bencze, J. Macromol. Sci., Pure Appl. Chem., A34, 1977 (1997).

23. H. C. Brown, "Organic Synthesis via Boranes," Wiley-Interscience: New York, N.Y., 1975, p 184.

24. K. Sonogashira, Y. Tohda, and N. Hagihara, Tetrahedron Lett., 50, 4467 (1975)

25. L. Brandsma, H. Hommes, R. L. P. de Jong, and H. D. Verkruijsse, Recl. Trav. Chim. Pays-Bas, 104, 226 (1985).

26. The polymerization of $o$-Me-phenylacetylene was too fast to monitor the monomer consumption.

27. H. Kaneshiro, T. Masuda, and T. Higashimura, Polym. Bull., 35, 17 (1995).

28. T. Masuda, T. Izumikawa, Y. Misumi, and T. Higashimura, Macromolecules, 29, 1167 (1996).

29. T. Mizumoto, T. Masuda, and T. Higashimura, Macromol. Chem. Phys., 196, 1769 (1995). 